\title{
CrimRxiv
}

\section{Review 1 of "Socialization across the three stages of the Correctional Service of Canada's correctional officer training program: An ethnographic study"}

Adrian Marrison

Published on: Jul 13, 2021

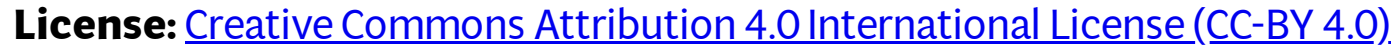


Vote: Publish pending minor changes

[For votes to count, referees must reasonably explain why they voted as they did. Thus, please explain your vote. If you voted to publish pending minor changes, specify each change, why it is needed, and, possibly, how it should/could be done.]

I enjoyed reading your paper titled: Socialization across the three stages of the Correctional Service of Canada's correctional officer training program: An ethnographic study. I found it to be well-written and competently executed. You are very clear about joining the scholarly conversation on correctional officers, clearly outlining the research gap on training within the prison literature. Except for a handful of studies, there has been little scholarly enquiry into correctional officer training. Indeed, whilst prison adjustment has been studied (such as the classics of Sykes, 1958; Clemmer, 1940; and others), this has been overwhelmingly focused on prisoners. As such, your paper contributes to the understudied area of adjustment in correctional officers.

In reviewing this space, you have developed intertextual coherence nicely by engaging with insights from the literature on correctional officer culture. It was good to see that you draw on a number of key works here such as Crawley, 2004; Crawley \& Crawley, 2008; Crewe et al., 2011; Sparks et al., 1996. The insights from these studies are presented clearly, in short suggesting that whilst culture varies considerably between prison establishments, there are some core tenets around solidarity, loyalty and courage that might be expected to regulate how correctional officers relate to each other and the prisoners they are charged to care for. The kind of culture that is socialized into new recruits through their training, and what this achieves, is an interesting question worthwhile pursuing, particularly considering the research gap on correctional officer training.

The main secondary literature on organizational socialization you use is well suited to help you partially fill this gap, with Van Maanen \& Schein as the main theoretical grounding. The use of this is well justified, particularly due to its strong links with to the similar occupation of policing. Through this lens the core takeaways become clear: new recruits are bonded but split, where they share solidarity but must surveil each other at the same time. Through a variety of techniques - such as testing, reprimands and symbolic rituals - loyalty to the organization becomes a central element of the training. A culture of solidarity fractures as the expectation is for recruits to report the 
negative behaviors of their colleagues. This "caveated camaraderie" you refer to seeds mistrust, or a reservation of trust within the cohort. It is in essence a loyalty play off between colleagues and the behavior valued by the CSC. Whether these behavioral ideals are carried forward into the prison is an open question: one you acknowledge would be a worthwhile avenue for future research. Indeed, as the correctional officer role is already full of tensions (see Tracy, 2004), 'caveated comradery' may get imported into the prison by the recruits as an additional tension in the onboarding process.

\section{Methodological Clarity}

Whilst I am overall very positive about your paper, I believe it can be improved through some minor corrections. First, the paper would benefit from enhanced methodological clarity. At present, the methods section is oriented towards the empirical context, but it would also be useful to outline the process of data analysis in generating the themes you identify. Whilst I understand that this method of analysis does not involve creating coding schemes or applying mechanical steps, there will have been a process by which you moved from data/experience to insights. Recent work in the journal typically provides some overview of this movement (see for example Aujla, 2021 or Williams \& Rumpf, 2020). Outlining and justifying these series of moves will aid clarity, transparency, and a basis for other researchers to follow suit or critique. For example, did you derive several themes before selecting the most salient for deeper analysis? Was this done purely through your own reflections, using a fellow researcher to ask probing questions, or some other means? Did you use the themes reflected from your own experience as plausible entry points into the data you have on the recruits? In short, I would like to see some outline of how you came to your findings.

\section{Literature}

It would be useful to show engagement with Arnold's (2013) piece on experiencing the prison officer training course in the UK, Morrison's (2018) and Morrison \& Maycock's (2021) work on prison officer socialization in Scotland. In addition, you give two definitions for organizational socialization (one by Farnese et al., 2016 and another by Van Maanen, 1975), but just one is sufficient. The sub-heading "results" would be useful to change to "findings" as this is more common for qualitative research. Finally, there are a number of typos (that inevitably occur on any long manuscript), so it would benefit from proofreading. Overall though, I believe in the value of your paper and think it adds a worthwhile contribution to the understudied area of correctional officer socialization in Canada. 


\section{References}

Arnold, H. (2013). The experience of prison officer training. In Understanding prison staff (pp. 416-435). Willan.

Aujla, W. (2021). Policing Perspectives Concerning Confusion and Uncertainty in Policing Practices with "Honour"-Based Crimes and Forced Marriages. Journal of Qualitative Criminal Justice \& Criminology. https://doi.org/10.21428/88de04a1.6a7f08f2

Clemmer, D. (1940). The prison community. Boston: Christopher Publishing.

Crawley, E. (2004). Emotion and performance: Prison officers and the presentation of self in prisons. Punishment \& Society, 6(4), 411-427.

Crawley, E., \& Crawley, P. (2008). Understanding prison officers: Culture, cohesion and conflict. In J. Bennett, B. Crewe, \& A. Wahidin (Eds.), Understanding prison staff (pp. 134-152). Abingdon: Routledge.

Crewe, B., Liebling, A., \& Hulley, S. (2011). Staff culture, use of authority and prisoner quality of life in public and private sector prisons. Australian \& New Zealand Journal of Criminology, 44(1), pp.94-115.

Morrison, K. (2018). Professionalism and affective learning for new prison officers: learning values, attitudes and behaviours in training at the Scottish Prison Service. In S. Loo (Ed.), Multiple Dimensions of Teaching and Learning for Occupational Practice. London: Routledge.

Morrison, K. and Maycock, M. (2021). Becoming a prison officer: An analysis of the early development of prison officer cultures. The Howard Journal of Crime and Justice, 60(1), pp.3-24.

Sparks, R., Bottoms, A., \& Hay, W. (1996). Prisons and the problem of order. Oxford: Clarendon.

Sykes, G. M. (1958). The society of captives. Princeton: Princeton University Press.

Tracy, S.J. (2004). Dialectic, contradiction, or double bind? Analyzing and theorizing employee reactions to organizational tension. Journal of Applied Communication Research, 32(2), pp.119-146. 
Williams, Q., \& Rumpf, C. (2020). What's After Good?: The Burden of PostIncarceration Life. Journal of Qualitative Criminal Justice \& Criminology. https://doi.org/10.21428/88de04a1.d5d7d868 